\title{
A FORMAÇÃO DE PROFESSORES E A TEORIA CRÍTICA: ENTRE O MERCADO E A EMANCIPAÇÃO HUMANA
}

\author{
LA FORMACIÓN DEL PROFESORADO Y LA TEORÍA CRÍTICA: ENTRE EL \\ MERCADO Y LA EMANCIPACIÓN HUMANA
}

\author{
TEACHER TRAINING AND CRITICAL THEORY: BETWEEN MARKET AND HUMAN \\ EMANCIPATION
}

\author{
Andréia da Cunha Maleiros SANTANA ${ }^{1}$ \\ Mariana Civalsci CARDOSO ${ }^{2}$ \\ Taila Angélica Aparecida da SILVA ${ }^{3}$
}

RESUMO: A formação de professores sob o viés da perspectiva da teoria crítica constitui o tema deste artigo. Trata-se um artigo de cunho bibliográfico, que tem como objetivo geral promover uma reflexão de duas tendências na área da formação de professores, uma voltada para o mercado de trabalho no contexto da globalização e do neoliberalismo e outra voltada para a emancipação do ser humano. No contexto atual, constata que se a formação não atender ao mercado de trabalho, terá sido inútil, no entanto, uma formação crítica nos fará questionar que tipo de formação esta sociedade deseja. Conclui que a formação de professores não pode ser aligeirada apenas para atender os interesses de mercado, mas deve contribuir para a formação do profissional, articulando teoria e proporcionando a difusão dos saberes historicamente produzido.

PALAVRAS-CHAVE: Formação de professores. Teoria crítica. Mercado. Ensino superior.

RESUMEN: La formación del profesorado bajo el sesgo de la perspectiva de la teoría crítica constituye el tema de este artículo. Se trata de un artículo de cuño bibliográfico, que tiene como objetivo general promocionar una reflexión de dos tendencias en el área de la formación del profesorado, una direccionada al mercado laboral en el contexto de la globalización y del neoliberalismo y otra direccionada para la emancipación del ser humano. En el contexto actual, se constata que si la formación no satisfaz al mercado laboral, tendrá sido inútil, sin embargo, una formación crítica nos pondrá a cuestionar qué tipo de formación desea esta sociedad. Concluye que la formación del profesorado no puede ser aligerada solo por satisfacer a los intereses del mercado, pero debe contribuir para la formación del profesional, articulando teoría y proporcionando la difusión de los saberes históricamente producido.

${ }^{1}$ Universidade Estadual de Londrina (UEL), Londrina - PR - Brasil. Docente do Programa de Pós-Graduação em Educação e do mestrado profissional. Prof. Letras. Doutora em Educação Escolar. ORCID: https://orcid.org/00000003-0231-657. Lattes: http://lattes.cnpq.br/4835407468291098. E-mail: andreiacunhamalheiros@gmail.com ${ }^{2}$ Universidade Estadual de Londrina (UEL), Londrina - PR - Brasil. Mestre pelo Programa de Pós-Graduação em Educação. ORCID: https://orcid.org/0000-0002-0726-486. Lattes: http://lattes.cnpq.br/8001720304975709. Email: marianapedag@hotmail.com

${ }^{3}$ Universidade Estadual de Londrina (UEL), Londrina - PR - Brasil. Mestranda do Programa de Pós-Graduação em Educação. ORCID: https://orcid.org/0000-0001-7780-0848. Lattes: http://lattes.cnpq.br/4021989627298735. E-mail: tailaangelicasilva@gmail.com

RIAEE - Revista Ibero-Americana de Estudos em Educação, Araraquara, v. 14, n. esp. 4, p. 2003-2016, dez., 2019. E-ISSN: $1982-5587$. DOI: https://doi.org/10.21723/riaee.v14iesp.4.12924 
PALABRAS CLAVE: Formación del profesorado. Teoría crítica. Mercado. Enseñanza superior.

ABSTRACT: Teacher training on the perspective of critical theory is the theme of this article. This is a bibliographical article, whose general objective is to promote a reflection of two trends in the area of teacher training, one focused on the labor market in the context of globalization and neoliberalism and another focused on human emancipation. In the current context, it notes that if training does not meet the labor market, it would have been pointless, however, critical training will make us question what kind of training this society wants. It concludes that the formation of teachers cannot be lightened only to attend the market interests, but must contribute to the professional formation, articulating theory and providing the diffusion of the historically produced knowledge.

KEYWORDS: Teacher training. Critical theory. Market. Higher education.

\section{Introdução}

Este texto é fruto de uma pesquisa bibliográfica cujo principal objetivo é apresentar uma reflexão que evidencia duas tendências na área de formação de professores, uma voltada para o mercado de trabalho no contexto da globalização e do neoliberalismo e outra voltada para a emancipação do ser humano. Ambas têm características e objetivos diferentes. O mercado exige profissionais polivalentes, flexíveis, com conhecimentos técnicos e que possuam habilidades múltiplas. Quem não estiver capacitado de acordo com estas exigências será excluído do processo produtivo, o que significa desemprego. Nesta concepção, a educação, em todos os níveis, é vista como uma mercadoria.

Diferentemente desta formação utilitarista, a teoria crítica apresenta uma outra visão a respeito da educação, uma visão que pode guiar um novo modelo de formação de professores. Para Adorno (1995c), é necessário pensar a Educação como geradora da autorreflexão, pois somente ela pode fomentar o esclarecimento cultural, a resistência aos modismos e à instrumentalização da razão. O profissional deve ter sólida formação para poder identificar às pressões existentes em nossa sociedade e fazer escolhas capazes de resistir a estas pressões, a formação do indivíduo deve ser crítica e reflexiva para que possa ultrapassar os valores imediatistas defendidos pelo mercado. 


\section{Formar para o mercado ou para a emancipação? Eis a questão}

O Ensino Superior vem sofrendo grandes transições em sua estrutura ao longo do século XXI, isso porque suas atribuições estão cada vez mais voltadas à formação de mão de obra qualificada ao mercado de trabalho. A universidade é pressionada a formar rapidamente o aluno como trabalhador para o mercado. Esta formação altamente instrumentalizada fez com que Santos e Almeida Filho afirmassem que há uma espécie de crise causada pela “descaracterização intelectual da universidade" (2008, p. 15).

As regras desta sociedade são determinadas pelo poderio econômico e as políticas educacionais e são projetadas segundo as exigências do mercado, com uma forte influência dos países que dominam a economia. Para Antunes (2010), a educação capitalista é a educação taylorista-fordista: formal, parcelada e hierarquizada, elaborada por uma gerência científica, executada por trabalhadores, qualificando para o mercado de trabalho e não para questioná-lo.

A universidade, neste contexto, tem oferecido uma formação utilitarista advinda da racionalidade técnica, que tem por finalidade se opor a razão crítica para atender às necessidades da prática profissional, deixando em segundo plano a formação do conhecimento, a formação epistemológica do profissional, tal realidade envolve diferentes carreiras, inclusive a do professor. Para Mizukami et al. (2002), o modelo da 'racionalidade técnica' não dá mais conta da formação docente, o que leva os autores a apontarem a 'racionalidade prática' como uma nova forma de entender a formação, por isso há uma grande valorização da prática e dos saberes advindos dela em detrimentos dos conhecimentos historicamente produzidos, trata-se de um reflexo da política neoliberal.

A educação para o mercado objetiva uma formação geral e polivalente, visando a qualificação de mão de obra para o mercado. Marcuse (1979, p. 111) comenta: “[...] a racionalidade está a serviço da rentabilidade, a qual está orientada pelo cálculo sistemático e metódico do capital". Os consumidores se tornam o objeto principal da indústria cultural, trazendo assim uma semiformação através dos conceitos influenciados por esta lógica. Sem parecer uma manipulação, a Indústria Cultural está sendo fortalecida pela égide da padronização de forma sutil através da cultura, buscando como foco principal o seu lucro na sociedade e nas relações humanas, conforme o autor Zuin analisa:

A lógica do equivalente acaba por fundamentar os alicerces do raciocínio dicotômico que consagra os rótulos daqueles que são considerados "perdedores" ou "vencedores", por exemplo. Dificulta-se a sobrevivência do pensamento crítico numa sociedade em que os indivíduos se transformam em "caixas de ressonância" de mensagens que seduzem pelo incentivo à 
integração, muitas vezes cega, a um coletivo regido por uma palavra de ordem autoritária (ZUIN, 2011, p. 11).

Nesse processo de transmissão de valores mercadológicos sobre a vida humana, a Indústria Cultural acaba prejudicando a vida das pessoas em diversos aspectos, principalmente em um contexto social marcado pela ausência de posicionamentos reflexivos e críticos. Todos os indivíduos acabam sendo influenciados por esses ditames mercadológicos, perpetuando em suas escolhas, comportamentos que fazem com que o homem cada vez mais se afaste de suas necessidades essenciais em troca de necessidades fabricadas, supérfluas, da sociedade de consumo.

Neste contexto, dentro da sociedade de consumo, a educação se torna um produto do capital, e passa a ser tratada como uma mercadoria, e dentro do contexto mercadológico da educação no âmbito da formação de professores, o número de cursos de formação de professores ofertados é ampliado para atender uma demanda de mercado, pretende-se com isto resolver o problema quantitativo, a questão qualitativa fica para segundo plano.

Os reflexos das políticas neoliberais para a formação docente foram consolidados através da LDB (BRASIL, 1996), nela a formação de professores deve ser realizada no ensino superior, independente da modalidade de ensino. Para Saviani (1997), a aprovação da atual Lei de Diretrizes e Bases da Educação (LDB 9.394) foi um processo das forças conservadoras da educação brasileira, articuladas aos interesses da classe dominante, o autor defende a ideia que estas bases legais refletem uma educação centrada na cultura imediatista, resultado da alienante cultura de massas.

Como resultado da aprovação desta lei, houve um aumento na procura de uma formação em nível superior em cursos de curta duração e/ou à distância, ocasionando também um aumento no número de instituições de ensino superior com cursos rápidos, nem sempre de boa qualidade, mas que oferecem, no término do curso, o tão sonhado certificado de conclusão, o qual é uma exigência da sociedade capitalista para se conseguir um bom emprego, pois este é sinônimo de qualidade e atesta esse indivíduo estar apto para exercício e prática da função, mesmo que a sua formação não tenha lhe proporcionado uma reflexão significativa para o exercício de sua prática.

Surge neste cenário uma democratização falseada por meio da expansão do Ensino Superior na modalidade EaD (Educação à Distância), sobretudo em instituições privadas, com a oferta de cursos aligeirados, superficiais, rasos, sem a estrutura para oferecer uma formação 
que proporcione conhecimentos científicos e elaborados, capazes de assegurar conhecimentos que reflitam de forma significativa na prática docente.

Tabela 01 - Formação de Professores

\begin{tabular}{|c|c|c|c|c|c|c|}
\hline \multicolumn{7}{|c|}{ Brasil: 2001 e 2017} \\
\hline \multirow[t]{2}{*}{ Ano } & \multirow{2}{*}{$\begin{array}{l}\text { Número Total de } \\
\text { Matrículas: } \\
\text { Licenciatura }\end{array}$} & \multicolumn{2}{|c|}{$\begin{array}{l}\text { Matrículas no ensino } \\
\text { presencial }\end{array}$} & \multirow{2}{*}{$\begin{array}{l}\text { Número Total } \\
\text { de Matrículas: } \\
\text { Licenciatura }\end{array}$} & \multicolumn{2}{|c|}{ Matrículas EaD } \\
\hline & & $\begin{array}{l}\text { Rede } \\
\text { Pública }\end{array}$ & $\begin{array}{l}\text { Rede } \\
\text { Privada }\end{array}$ & & $\begin{array}{l}\text { Rede } \\
\text { Pública }\end{array}$ & $\begin{array}{l}\text { Rede } \\
\text { Privada }\end{array}$ \\
\hline 2001 & 928.022 & 428.649 & 499.373 & 5359 & 5359 & 0 \\
\hline 2009 & 1405.791 & 554.944 & 850.847 & 420.094 & 97.523 & 330.207 \\
\hline 2017 & 1589.440 & 2.152 .752 & 1.073 .497 & 649.137 & 2.045 .356 & 6.241 .307 \\
\hline
\end{tabular}

Fonte: Dados de 2001 e 2009 - Adaptação de Gatti et al. (2010, p. 104)

Como evidenciado pelos dados acima, os cursos em $\mathrm{EaD}$ foram ampliados, eles foram idealizados como um meio para promover a democratização/expansão do ensino. Segundo informações do INEP “Na EaD, predominam os cursos de licenciatura” (INEP, 2017, p. 07), por isso a importância de conhecer como eles estão formando os professores. Para Belloni e Peters há muitas características negativas na formação nesta modalidade:

Educação a distância é um método de transmitir conhecimento, competências e atitudes, que é racionalizado pela aplicação de princípios organizacionais e de divisão do trabalho, bem como pelo uso intensivo de meios técnicos, especialmente com o objetivo de reproduzir material de ensino de alta qualidade, o que torna possível instruir um número maior de estudantes, ao mesmo tempo, onde quer que eles vivam. É uma forma industrializada de ensino e aprendizagem (BELLONI, 2008, p. 27).

Alves (2005) analisa as particularidades da $\mathrm{EaD}$, com base em semelhanças no processo de produção industrial fordista do ocidente, a partir da $2^{\text {a }}$ Guerra Mundial, para os autores, esse padrão de produção apresenta as seguintes características: racionalização, planejamento, padronização, mecanização, linha de montagem, divisão do trabalho, produção em massa, concentração dos recursos e centralização administrativa. Estas características foram aproveitadas no ensino à distância e resultam numa formação mais econômica e rápida do profissional.

Tais características nos permitem afirmar que os pressupostos teóricos da educação à distância ainda são superficiais e necessitam de maior aprofundamento, embora tenhamos plena certeza que os princípios mercadológicos e utilitaristas não são exclusividades da educação à distância e estão presentes também em muitos cursos de licenciatura presencial, pois fazem parte do ideário pós-moderno. 
Saviani (2007) considera que a difusão dos ideais da pós-modernidade e da tecnologia implantaram diversos conceitos referentes à educação, como eficiência, eficácia e competências. Tendo como base estes ideais, o indivíduo deve buscar conhecimentos de acordo com as suas capacidades e competências para se manter competitivo no mercado de trabalho.

A educação passa a ser entendida como um investimento em capital humano individual que habilita pessoas para a competição pelos empregos disponíveis. A teoria do capital humano foi, pois, refuncionalizada e é nessa condição que ela alimenta a busca de produtividade na educação (neoprodutivismo) (SAVIANI, 2007, p. 428).

O "neoprodutivismo" é o conceito recorrente deste universo e traz consigo a ideia do desenvolvimento de novas competências que sejam úteis ao mercado, neste cenário, qual é a utilidade de uma consciência crítica e de um ensino capaz de favorecer o questionamento do saber técnico? Nenhuma. O trabalhador crítico pode questionar as suas condições de trabalho e os seus proventos, por isso é desejável que o trabalhador tenha apenas a formação necessária para se encaixar no mercado de trabalho não para questioná-lo.

Adorno (1995) apresenta uma proposta capaz de fomentar a reflexão e o senso crítico no processo educacional, o autor faz referência a teoria do conhecimento humano e questiona o uso desmedido da técnica, que tem tornado o sujeito um mero objeto de dominação, impondolhe uma adaptação ao sistema produtivo.

Adorno fundamenta o seu raciocínio filosófico a partir de pressupostos que desconfiam da relação entre a visão científica do mundo e dos homens e define a Técnica, como:

Não se sabe com certeza como se verifica a fetichização da técnica na psicologia individual dos indivíduos, onde está o ponto de transição entre uma relação racional com ela e aquela supervalorização, que leva, em última análise, quem projeta um sistema favorito para conduzir as vítimas a Auschwitz com maior rapidez e fluência, a esquecer o que acontece com essas vítimas em Auschwitz (ADORNO,1995, p. 133).

A consciência do trabalhador é alienada, a sua força de trabalho foi convertida em mercadoria, em valor de troca. As pessoas trabalham em troca do dinheiro, este dinheiro lhe garante o acesso aos bens de consumo, esses satisfazem as suas necessidades momentâneas criadas pela sociedade do consumo. O "fetiche" pode dominar a práxis e a consciência do indivíduo. O "fetiche" quer transformar em natural/normal o que é social. Assim, a força do trabalho humano não teve como princípio ser mercadoria, porém converteu-se em tal por meio das mudanças sócio-históricas. Dessa forma, o fetiche, ponderado por Adorno, ocorre quando 
a técnica devidamente acabada substitui a perfeição dentro dos parâmetros da sociedade (ADORNO, 1999).

Para Adorno (1995, p. 132), a técnica se apoia em saber como, saber fazer, saber técnico:

[...] na relação atual com a técnica existe algo de exagerado, irracional, patogênico. Isto se vincula ao véu tecnológico. Os homens inclinam-se a considerar a técnica como sendo algo em si mesma, um fim em si mesmo, uma força própria, esquecendo que ela é a extensão do braço dos homens.

O saber se torna uma aquisição e pode se igualar a coisas, "pessoas que se enquadram cegamente em coletivos convertem a si próprios em algo como um material, [...] Isto combina com a disposição de tratar outros como sendo uma massa amorfa” (ADORNO, 1995, p. 129).

A racionalidade técnica e instrumental estimula as práticas de formação orientando-as para a exterioridade dos sujeitos, ou seja, para a prática que deverão conhecer e manipular instrumentalmente. Investem nas práticas operacionalizadas em um curto espaço-tempo da formação e na neutralidade dos sujeitos.

Podemos analisar sistematicamente a modernidade, assumindo um papel tão proeminente que a situação da sociedade e da cultura nesta conjuntura pode ser resumida como um fenômeno do declínio da experiência. O estabelecimento da modernidade foi acompanhado, portanto, de um empobrecimento abundante da experiência:

\footnotetext{
Qual o valor de todo o nosso patrimônio cultural, se a experiência não mais o vincula a nós? A horrível mixórdia de estilos e concepções do mundo do século passado mostrou-nos com tanta clareza aonde esses valores culturais podem nos conduzir, quando a experiência nos é subtraída, hipócrita ou sorrateiramente, que é hoje em dia uma prova de honradez confessar nossa pobreza. Sim, é preferível confessar que essa pobreza de experiência não é mais privada, mas de toda a humanidade. Surge assim uma nova barbárie (BENJAMIN, 1985, p. 115).
}

Para Benjamin, a pobreza da experiência atribuída pela modernidade consistiu na impossibilidade da erfahrung (experiência autêntica), ou seja, em uma barbárie na incoerência da comunicação de experiência coletiva, no entendimento da leitura e na compreensão de mundo. Sendo assim, a ausência desta experiência autêntica evidencia um modo de perceber a Modernidade e suas manifestações simbólicas secundárias e irrelevantes, segundo este autor, a experiência, nos tempos modernos, foi substituída pela erlebnis (experiência inautêntica) a vivência do indivíduo isolado.

O ensino pautado dentro de conceitos práticos, técnicos e de experiências inautênticas é ampliado, segundo Kincheloe (1997, p. 35),“os alunos e professores não são encorajados para questionar porque eles tendem a pensar como o fazem sobre eles mesmos, sobre o mundo em 
torno deles e suas relações com o mundo", por estar acostumado a não refletir de modo crítico durante a sua formação, este profissional acabará por reproduzir a estrutura na qual foi formado. Com isto, professores e alunos estão, a cada dia, mais envolvidos com a cultura do status quo, cultura esta que não permite a diversidade, a crítica e a descoberta do novo.

Para alterar tal contexto, a universidade deve formar o futuro professor para que este tenha consciência crítica e autônoma e não proporcionar ao licenciando um simples saber técnico/instrumental. De acordo com Adorno (1995), a consciência objetivada, gira em torno de si e se caracteriza como uma cabeça sem vida e esta não é a função da universidade, o seu papel é formar cidadãos com consciência reflexiva e crítica para saberem se reconhecer como cidadãos de direitos e saber viver em sociedade.

A cultura de massa transformou o conhecimento das pessoas em catalizadores de informações superficiais e técnicas, tornando o indivíduo cada vez mais pobre de sabedoria e conhecimento. O indivíduo formado por influência da Industria $\mathrm{Cultural}^{4}$, fica impossibilitado de refletir com consciência crítica acerca da resistência à barbárie ${ }^{5}$ na educação, como pode um professor que não tenha tal consciência crítica formar um aluno consciente? Não é possível. Para que o estudante da educação básica seja crítico e autônomo, ele deve ser formado por um professor também crítico e autônomo. A barbárie é um ato de violência, pois ela retira de forma grosseira a condição do progresso de alguém.

Os parâmetros do neoliberalismo que influenciam a educação produzem, segundo Adorno, uma cultura de massa, padronizando o ensino e a formação do indivíduo, promovendo a alienação da consciência deste sujeito perante a sociedade e falseando um progresso de cultura. A Educação é o único instrumento contra a barbárie, é o meio para a emancipação do indivíduo, pois o papel da Educação é proporcionar um ensino crítico reflexivo e consequentemente emancipatório. "Se a barbárie é justamente o contrário da formação cultural, então a desbarbarização das pessoas individualmente é muito importante[...]. Este deve ser o objetivo da escola, por mais restritos que sejam seu alcance e suas possibilidades" (ADORNO apud PUCCI, 2007, p. 3)

Desta forma, a universidade deve oferecer condições para cultivar a capacidade reflexiva do professor, de acordo com Alarcão, "O pensamento reflexivo é uma capacidade.

\footnotetext{
${ }^{4}$ O termo Indústria Cultural foi criado por Max Horkheimer (1895-1973) e Theodor Adorno (1903-1969) e apresenta as seguintes características: Sociedade de consumo, alienação e reificação, produtos culturais impregnados de uma cultura simplificada, cultura de massa, entre outros. Disponível em: http://twixar.me/9Gh3 ${ }^{5}$ De acordo com Adorno, apud Pucci (2006, p. 3), entende-se por barbárie, "momentos repressivos e regressivos no conceito de educação"; "práticas de atos que denunciam a deformidade, o impulso destrutivo e a essência mutilada das pessoas".

RIAEE - Revista Ibero-Americana de Estudos em Educação, Araraquara, v. 14, n. esp. 4, p. 2003-2016, dez., 2019. E-ISSN: 1982-5587. DOI: https://doi.org/10.21723/riaee.v14iesp.4.12924 (c) BY-NC-SA 
Como tal, não desabrocha espontaneamente, mas pode desenvolver-se. Para isso, tem de ser cultivado e requer condições favoráveis para o seu desabrochar" (1996, p. 9). Este saber fruto do pensamento reflexivo é proveniente de uma formação que articule teoria e prática e não, simplesmente, a prática pela prática. Alarcão (1996, p. 3) faz a seguinte observação em relação ao saber da prática do professor reflexivo:

A reflexão baseia-se na vontade, no pensamento, em atitudes de questionamento e curiosidade, na busca da verdade e da justiça. Sendo um processo simultaneamente lógico e psicológico, combina a racionalidade da lógica investigativa com a irracionalidade inerente à intuição e à paixão do sujeito pensante; une cognição e afetividade num ato específico, próprio do ser humano.

Nesta ótica, o professor deve ser visto como um produtor de saberes que reflete sobre sua prática e que é capaz de pesquisar. O professor deve pesquisar sobre sua prática, pois sem pesquisa não há uma prática docente significativa e o indivíduo permanece no senso comum.

A formação inicial do professor deve proporcionar subsídios conceituais para que ele tenha acesso aos saberes que nortearam sua prática, pois não há prática que não esteja alicerçada numa teoria. Por meio das transformações ideológicas implementadas pela globalização e pelo neoliberalismo, o professor acaba perdendo a visão e o foco do seu trabalho devido às multifunções e saberes rasos que lhe são oferecidos, dando lugar ao pragmatismo exacerbado, uma formação deficitária do docente e uma sobrecarga exaustiva de trabalho são dois pontos cruciais da educação no contexto capitalista.

O interesse do capital em investir na Educação e em direcionar as instituições de ensino superior a desenvolver no indivíduo o "aprender fazendo"/“aprender praticando" e toda a hipervalorização da prática tem como intenção fazer com que os estudantes procurem conhecimentos por sua utilidade e funcionalidade pragmática. Os pilares que sustentam a Educação sob esta ótica são fundamentados no utilitarismo e no individualismo, retirando da aprendizagem o conteúdo significativo, restando apenas ideias vazias e um saber imediato, tornando o indivíduo adaptável ao mercado de trabalho.

Esta lógica, de acordo com Hannah Arendt (2005, p. 6), é uma forma utilitarista do ensino e resulta na negligência dos conteúdos, pois uma das crises da modernidade que reflete na Educação "é a influência da psicologia moderna e das doutrinas pragmáticas, a pedagogia tornou-se uma ciência do ensino em geral ao ponto de se desligar completamente da matéria a ensinar".

Ainda segundo a autora, esta pedagogia moderna colaborou para a crise na Educação, pois os conhecimentos científicos foram secundarizados e os cursos aligeirados visando uma RIAEE - Revista Ibero-Americana de Estudos em Educação, Araraquara, v. 14, n. esp. 4, p. 2003-2016, dez., 2019. E-ISSN: 1982-5587. DOI: https://doi.org/10.21723/riaee.v14iesp.4.12924 
certificação em massa. Isso nos faz refletir sobre a falta dos conteúdos historicamente acumulados que são essenciais para o conhecimento global do futuro professor, Cambi ressalta que:

Com o advento da "indústria cultural" e dos mass media produziu-se uma verdadeira e própria revolução pedagógica, talvez uma das mais fundamentais de nosso tempo, que justamente no segundo pós-guerra manifestou-se em toda a sua potência, de difusão e de incidência. Os chamados "persuasores ocultos" ocuparam uma posição cada vez mais ampla na formação do imaginário coletivo, influindo diretamente sobre a consciência pessoal de cada indivíduo, sobre seus níveis de aspiração, sobre seus gostos, comportamentos, consumos, chegando a regular em larga medida a sua identidade e, portanto, também a das massas (CAMBI, 1999, p. 630).

Segundo Adorno, na Indústria Cultural tudo se transforma em negócio, a educação também. Ele diz: "Enquanto negócios, seus fins comerciais são realizados por meio de uma sistemática e programada exploração de bens considerados culturais" (ADORNO; HORKHEIMER, 1985, p. 134).

A Indústria Cultural só se interessa por pessoas enquanto consumidores dos seus produtos. O sujeito é visto como um mero produto, uma mercadoria para troca. A indústria cultural impede a formação de indivíduos autônomos ou capazes de tomarem decisões emancipatórias a este sistema capitalista. Neste contexto, tudo se transforma em objeto passível de comprar, mesmo um curso superior, ele passa a ser consumido.

A nossa sociedade embora seja industrializada e moderna, não está livre de vivenciar situações de barbárie. A massificação gera a barbárie, que é a condição de existência da própria sociedade e para amenizar esta barbárie é necessário refletir sobre a sua condição de submissão a lógica da sociedade manipuladora. Por falta desta reflexão, desta criticidade, há uma ideologia sendo camuflada através da limitação no entendimento e consciência de alguns

Adorno traz o termo semiformação para designar esta formação defendido pelo mercado.

Que a semiformação, apesar do esclarecimento da ilustração e da difusão de informações e mesmo por seu intermédio se tornou a forma dominante da consciência contemporânea - é justamente isto que exige uma teoria mais ampla. A ideia de cultura não deve ser sacrossanta para ela, conforme é hábito da própria semiformação. A formação cultural (Bildung) nada mais é do que a cultura pelo lado de sua apropriação subjetiva. A cultura, porém, tem um caráter duplo. Ele remete de volta à sociedade e mediatiza entre a mesma e a semiformação. (ADORNO, 1979, p. 94) 
Segundo Pucci (1995, p. 56), o prefixo "semi” em Adorno, diz respeito a um caminho difícil de transpor ou a uma formação pela metade. A Cultura, ao mesmo tempo que deve se aproximar do processo formativo do homem, também se preocupa em desvendar sua autonomia. Podemos compreender que a semiformação é definida pelas determinações sociais, que impõe os moldes de produção, nos quais o sujeito tem que ser moldado para estar inserido neste meio. $\mathrm{O}$ único meio para resistir a estes moldes seria a capacidade da consciência crítica e reflexiva, que só é adquirida por meio da Educação. Adorno afirma que a semiformação é "o espírito tomado pelo caráter fetichista da mercadoria" (ADORNO, 1979, p. 108).

Adorno se preocupa com o processo formativo humano, para ele, este processo, não deve ser mercantilizado. Adorno também chama a atenção para o "fetichismo da técnica", que consiste numa idolatria por coisas, por máquinas em si mesmas, tal "fetichismo" está bastante presente no nosso contexto educacional, valoriza-se a tecnologia como se esta por si só pudesse garantir uma melhoria na qualidade da educação, esta hipervalorização da tecnologia está relacionada à indústria cultural.

Sob a dominação da indústria cultural, o indivíduo é levado a viver sob as novas perspectivas da ideologia social, marcadamente influenciada pelo avanço das novas tecnologias da informação, e que, por isso o torna um semiformado, um sujeito que encontra dificuldades em transpor o que culturalmente lhe é imposto.

A única forma de superar a razão instrumental, decorrente destas normativas da indústria cultural, é através da Educação, como única forma de resistência contra a força da indústria cultural, na medida em que esta possa facilitar o desenvolvimento da consciência crítica e reflexiva, capaz de permitir ao indivíduo desvendar as contradições da vida social. Esta educação não pode ser aligeirada, ela deve ser sólida e fomentar a constante reflexão sobre o homem, seu contexto e sua cultura

Se o Ensino não oferecer meios para a emancipação do sujeito se posicionar conscientemente diante da sociedade, este Ensino proporcionará uma falsa emancipação. Um professor formado no modelo mercadológico, que está integrado à indústria cultural, dificilmente conseguirá romper esta barreira e proporcionar aos seus alunos uma educação crítica e reflexiva. Os cursos de formação de professores, tal como toda formação universitária, têm o poder de emancipação, mas eles não podem se vender aos modismos das pedagogias modernas

O professor deve ter um posicionamento que fortaleça a formação humana, este profissional quando possui uma consciência emancipatória, deve buscar formas para traçar o seu projeto de formação e dos seus alunos para além das necessidades imediatas do mercado RIAEE - Revista Ibero-Americana de Estudos em Educação, Araraquara, v. 14, n. esp. 4, p. 2003-2016, dez., 2019. E-ISSN: 1982-5587. DOI: https://doi.org/10.21723/riaee.v14iesp.4.12924 
(GRAMSCI, 2001). Não há interesse do mercado em promover esta formação, por isso este professor deve ter consciência do papel da educação para toda a sociedade. Somente a educação tem o poder de emancipar o sujeito e fortalecer sua capacidade de resistência aos moldes estabelecidos e/ou pré-estabelecidos pela Industria Cultural.

\section{Considerações finais}

Vivemos num momento de crise marcado pela cultura do consumo e por uma sociedade guiada pelos valores mercadológicos, é comum as pessoas buscarem uma qualificação profissional sem levar em conta o tipo de formação que está sendo oferecido, se a formação não atender ao mercado de trabalho, para muitos ela terá sido inútil e terá descrédito para população em geral, no entanto, uma formação crítica e reflexiva nos fará questionar que tipo de formação esta sociedade marcada pelo capitalismo, pela globalização e pelo neoliberalismo deseja, será que o que ela deseja nos interessa enquanto seres humanos e enquanto uma sociedade? Os ensinamentos de Adorno e Horkheimer dizem que não, a consciência coisificada aceita incondicionalmente o que está dado, não questiona, se adapta. Para reverter esta situação somente uma educação emancipadora e crítica.

Esta educação deve ser realizada em todas as modalidades de ensino, entretanto, neste texto, abordamos a formação de professores por defender a ideia de que ela está ligada diretamente à qualidade do ensino, para que o estudante seja formado de modo crítico, o professor também precisa ter consciência dos valores existentes em nossa sociedade, ser resistente aos modismos pedagógicos e ter clareza da importância do seu papel social, o professor não pode ser substituído pela tecnologia, nem ter o seu papel secundarizado ou o seu trabalho fragmentado, cabe a ele planejar a aula, pensar na sua organização, selecionar os materiais didáticos necessários para cada turma de estudantes. Este professor não pode se deixar levar por um ensino artificial e mecanizado. Neste texto, citamos como exemplo de formação mercadológica e adepta à indústria cultural a educação à distância, mas os princípios que regem tal educação também podem ser vistos em cursos presenciais, o problema não está na modalidade (presencial ou à distância), mas na qualidade da formação oferecida.

Uma formação de professores capaz de promover a reflexão crítica dos estudantes não pode ser aligeirada, fragmentada, sujeita aos modismos e aos interesses do mercado, ela deve articular teoria e prática e proporcionar a difusão dos saberes historicamente produzidos, pois 
só desta forma o professor poderá exercer a sua função e contribuir para a formação de cidadãos conscientes das desigualdades sociais e que atuem contra as barbáries do mundo moderno.

\section{REFERÊNCIAS}

ADORNO, T. W. Soziologische Schriften. Frankfurt am Main: Suhrkamp, 1979.

ADORNO, T. W. Tempo Livre. In: ADORNO, T. W. Palavras e sinais: modelos Críticos 2. Tradução de Maria Helena Ruschel; supervisão de Álvaro Valls. Petrópolis: Vozes, p. 70-82, 1995.

ADORNO, T. W. Educação após Auschwitz. In: ADORNO, T. W. Educação e

Emancipação. Rio de Janeiro: Paz e Terra, p. 119-154, 1995.

ADORNO, T. W. O fetichismo na música e a Regressão da Audição. In: ADORNO, T. W. Textos Escolhidos. SP: Abril Cultural, 1999. Coleção: Os pensadores.

ADORNO, T. W.; HORKHEIMER, M. Dialética do Esclarecimento. Tradução de Guido Antonio de Almeida, Rio de Janeiro, Zahar Editores, 1985.

ALARCÃO, I. Ser Professor Reflexivo. In: ALARCÃO, I. (Org.). Formação reflexiva de professores: estratégias de supervisão. Editora Porto. Porto, Portugal, 1996. Disponível em: Ser_professor_reflexivo_Isabel_Alarcao.pdf. Acesso em: 3 abr. 2018.

ANTUNES, R. Adeus ao Trabalho? Ensaio sobre as Metamorfoses e a Centralidade no Mundo do Trabalho. 14. ed. São Paulo: Cortez, 2010.

ARENDT, H. Entre o passado e o futuro. São Paulo: Perspectiva, 2000

ALVES, M. C. B. Didática da educação a distância: interação pedagógica. 2005.

BENJAMIN, W. Obras escolhidas I: magia e técnica, arte e política. São Paulo: Brasiliense, 1985.

BRASIL. Ministério da Educação. Lei de Diretrizes e Bases da Educação Nacional. Lei n.9.394/96. Brasília, DF: MEC/SEF, 1996.

CAMBI, F. História da Pedagogia. São Paulo: Editora Unesp, 1999.

GRAMSCI, A. Cadernos do cárcere. Caderno 13: Maquiavel a política e o estado moderno. Rio de Janeiro: Civilização Brasileira, 2001.

KINCHELOE, J. L. Tradução de Nize Maria Campos Pellanda. A formação do professor como compromisso político: mapeando o pós-moderno. Porto Alegre: Artes Médicas, 1997.

MIZUKAMI, M. G. N.; REALI, A. M. M.; REYES, C. R.; MARTUCCI, E. M.; LIMA, E. F.; TANCREDI, R. M. S. P.; MELLO, R. R. Escola e aprendizagem da docência: processos de investigação e formação. São Carlos: EdUFSCar, 2002. 203p 
MARCUSE, H. A ideologia da sociedade industrial. Rio de Janeiro: Zahar, 1979.

PUCCI, B. (Org.). Teoria Crítica e Educação: A formação cultural na Escola de Frankfurt (2. ed). 1. ed. Petrópolis - RJ: Vozes/EDUFSCar, v. 1. 197 p, 1995.

PUCCI, B. Teoria Crítica e Educação. In: PUCCI, B. Teoria Crítica e Educação: a questão da formação cultural na Escola de Frankfurt. Petrópolis, RJ: Vozes; São Carlos, SP: EDUFSCAR, p. 11-58, 2007.

SANTOS, B. de S.; ALMEIDA FILHO, N. de (Orgs.). A Universidade no Século XXI: para uma universidade nova. Coimbra, 260 p., 2008. Disponível em:

http://www.boaventuradesousasantos.pt/media/A\%20Universidade\%20no\%20Seculo\%20XX I.pdf. Acesso em: 23 mar. 2018.

SAVIANI, D. Da nova LDB ao FUNDB: por uma outra política educacional. Campinas, SP: Autores Associados, 2007.

ZUIN, A. A. S. O Plano Nacional de Educação e as Tecnologias de Informação e

Comunicação. 2001. Disponível em: http://www.scielo.br/pdf/es/v31n112/16.pdf. Acesso: 15 de junho 2015.

\section{Como referenciar este artigo}

SANTANA, Andréia da Cunha Malheiros; CARDOSO, Mariana Civalsci; SILVA, Taila Angélica Aparecida da. A Formação de professores e a Teoria Crítica: entre o mercado e a emancipação humana. Revista Ibero-Americana de Estudos em Educação, Araraquara, v. 14, n. esp. 4, p. 2003-2016, dez., 2019. E-ISSN: 1982-5587. DOI: https://doi.org/10.21723/riaee.v14iesp.4.12924

Data de submissão: $25 / 06 / 2019$

Data de aceite: 27/07/2019

Data de publicação: 01/09/2019 